\title{
Article \\ Effect of Lap Length and Stiffness of Peel-Stop Fasteners in Single Lap Joints
}

\author{
Atsushi Takano *, Chao Li and Ryuta Kitamura
}

check for updates

Citation: Takano, A.; Li, C.; Kitamura, R. Effect of Lap Length and Stiffness of Peel-Stop Fasteners in Single Lap Joints. Appl. Sci. 2021, 11, 1086. https://doi.org/10.3390/ app11031086

Received: 17 December 2020

Accepted: 19 January 2021

Published: 25 January 2021

Publisher's Note: MDPI stays neutral with regard to jurisdictional claims in published maps and institutional affiliations.

Copyright: (C) 2021 by the authors. Licensee MDPI, Basel, Switzerland. This article is an open access article distributed under the terms and conditions of the Creative Commons Attribution (CC BY) license (https:// creativecommons.org/licenses/by/ $4.0 /)$.
Department of Mechanical Engineering, Faculty of Engineering, Kanagawa University, 3-27-1, Rokkakubashi, Kanagawa-ku, Yokohama 221-8686, Japan; lichao2686@gmail.com (C.L.); ft102093gj@kanagawa-u.ac.jp (R.K.)

* Correspondence: atakano@kanagawa-u.ac.jp; Tel.: +81-45-481-5661 (ext. 3371)

Featured Application: Metal-to-metal and/or composite-to-metal joints using adhesive and peel stoppers can be applied to ultra-light-weight rockets, fuselages of airplanes, satellites, and spacecraft.

Abstract: Strength tests on single lap joints with one adhesive (AV138/HV998) and one adhesive layer thickness $(0.5 \mathrm{~mm})$, three peel stoppers (brass bolt, nylon bolt and steel pin), and four lap lengths $(12.5 \mathrm{~mm}, 25 \mathrm{~mm}, 40 \mathrm{~mm}$ and $100 \mathrm{~mm})$ were conducted to investigate the effects of varying the lap length and stiffness of the peel-stop fasteners. Joint failure stress decreased, but failure force increased with lap length. Furthermore, joint failure stress was higher with the peel stopper. The effect of the brass-bolt peel stoppers was significant, whereas the effects of the nylon bolts and steel pins were smaller than that of the brass bolts. This indicates that the axial clamp strength and stiffness of the peel stopper are important factors in the shear strength of the lap. In addition, the effect of the stopper was negligible for the $12.5 \mathrm{~mm}$ lap. The reason is that the shear strength in the case of the $12.5 \mathrm{~mm}$ lap was large and thus the effect of the peel stopper was comparatively small. Moreover, the strength of the $100 \mathrm{~mm}$ lap reached the adherent material's strength.

Keywords: peel stopper; lap length; single lap joint

\section{Introduction}

Adhesive joints with mechanical fasteners are often used in aircraft and space vehicle structures for their high stiffness and reliability. Mechanical fasteners are used on adhesive joints to prevent bending failures due to offset loads and peel failures on the adhesives. Figure 1 shows the peel failure mode.

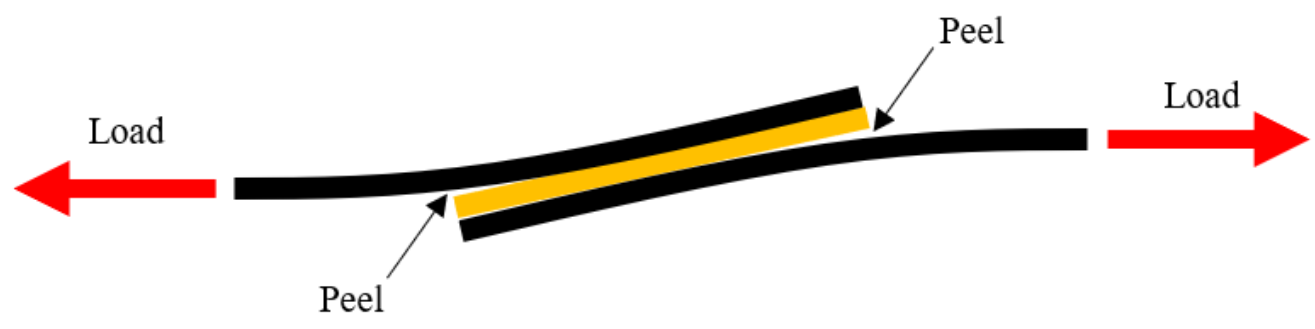

Figure 1. Peel failure mode.

Volkersen [1] analyzed the shear stress on the adhesive of a lap joint. Hart-Smith [2] improved the analysis by using a nonlinear stress strain curve including plastic strain. Goland and Reissner [3] analyzed the linear stress strain relation, in which they included the geometric nonlinear effects of an offset load. The peel stress, however, was similar to that of Volkersen's analysis [1]. Oplinger [4] and Ojalvo and Eidinoff [5] improved Goland and Reissner's analysis but again found no significant difference in peel stress from Volkersen. Awalekar et al. [6] reviewed the peel resistance of adhesives materials, and Kawashita [7] 
evaluated the fracture toughness in relation to bond-line thickness and peel-arm thickness. Pereira et al. [8] experimented and investigated numerically into the shear strength behavior of aluminum alloy adhesive lap joints. da Silva et al. experimented and investigated between plastic behavior of adhesives, bondline thickness and lap shear strength [9], Boutar et al. [10] studied the effect of surface treatment on the shear strength of aluminum adhesive single-lap joints using lap shear tests and surface inspection. Chowdhury et al. [11] tested and inspected the lap shear strength and fatigue behavior of a friction stir spot welded to dissimilar magnesium-to-aluminum joints with adhesive.

On the other hand, mechanical fasteners without adhesive have been used for mechanical joints. Mechanical fasteners using bolt-nut connections, however, face problems of loosening clamping force and low fatigue strength due to the spiral shape of the bolt-nut thread, wherein a high stress concentration factor occurs in the first bolt thread [12], and the load distribution in the threads is uneven. Slight pitch differences have to be introduced to increase fatigue strength and prevent loosening [13]. Also, for conventional mechanical joints using pure metal fasteners, there could be a problem of heat shorts on the fuselage structure [14]. Adhesive bonding without a peel-stop fastener has the advantage of not weakening the components to be joined; however, the reliability is generally not as high as mechanical fasteners. Therefore, adhesive bonding with peel-stop fasteners is often used when very reliable joints are required.

Despite the research mentioned above, no reliable or quantitative design method has yet been devised for single lap joints without peel stop fasteners. Of course, there is no mathematical model for a single lap joint with peel stop fasteners for the size, strength, and stiffness of the peel-stop fasteners. Thus, the authors decided to investigate the effect of the stiffness of peel-stop fasteners by testing fasteners of various shapes and materials. An understanding of the mechanism of strengthen using peel stoppers has worth and can lead to future mathematical models.

\section{Test Specimens}

\subsection{Overview}

Single lap adhesive joints made from aluminum alloy 2024-T3 (ultimate tension strength $440 \mathrm{MPa}$, yield tension strength $295 \mathrm{MPa}$ ) adherends were used. The width and thickness of each adherend were $25 \mathrm{~mm}$ and $1.6 \mathrm{~mm}$, respectively. The peel stoppers were located $3 \mathrm{~mm}$ from the tip of the adherend (Figure 2). Three types of peel stopper, i.e., M2-brass bolts (2 mm nominal diameter, ISO), M2-nylon bolts and 2-mm-diameter steel pins, were tested. Single lap joints without a peel stopper were also tested for comparison. Single adhesive, AV138/HV998 epoxy adhesive, was used. Four lap lengths, $12.5 \mathrm{~mm}$, $25 \mathrm{~mm}, 40 \mathrm{~mm}$, and $100 \mathrm{~mm}$, were tested. Table 1 summarizes the test specimens and sample numbers.

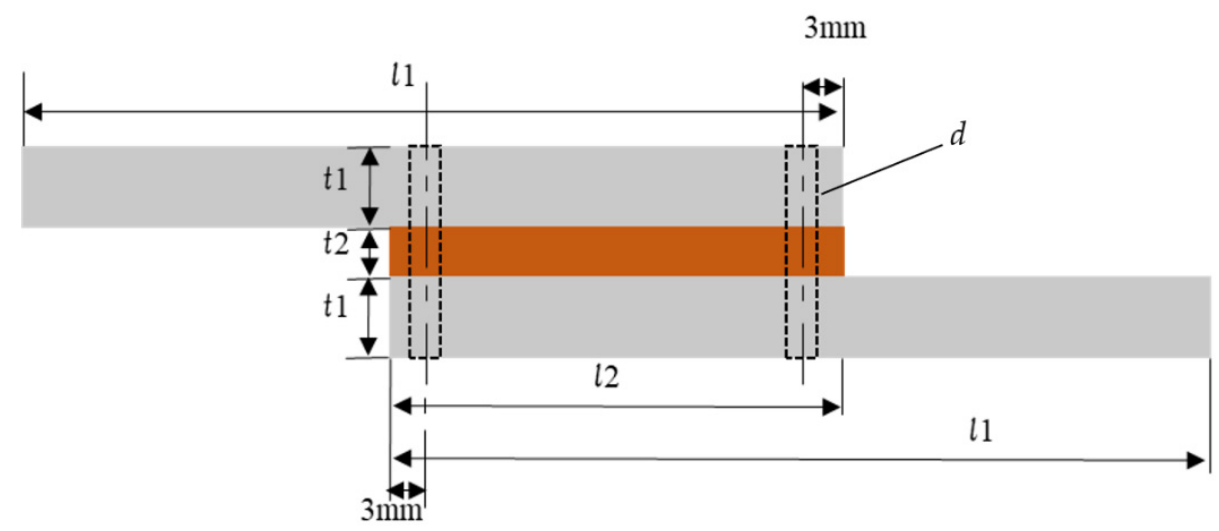

Figure 2. Location of peel stopper. 
Table 1. Summary of test specimens and sample numbers.

\begin{tabular}{ccccc}
\hline Adhesive & \multicolumn{4}{c}{ AV138/HV998 } \\
\hline Lap length [mm] & 12.5 & 25 & 40 & 100 \\
Without peel stopper & 2 & 2 & 2 & 2 \\
Brass bolt & 2 & 2 & 2 & 2 \\
Nylon bolt & 2 & 2 & 2 & 2 \\
Steel pin & 2 & 2 & 2 \\
Total & \multicolumn{2}{c}{32 samples } \\
\hline
\end{tabular}

\subsection{Concept of Selecting Peel Stoppers}

Single lap joints without a peel stopper were used to obtain the basis value. The M2brass bolt was used as a peel stopper with higher axial stiffness, while the M2-nylon bolt was used as one with 0a lower axial stiffness. The 2-mm-diameter steel pin was intended as a shear pin, not a peel stopper. Figure 3 shows a comparison between a bolt and pin.

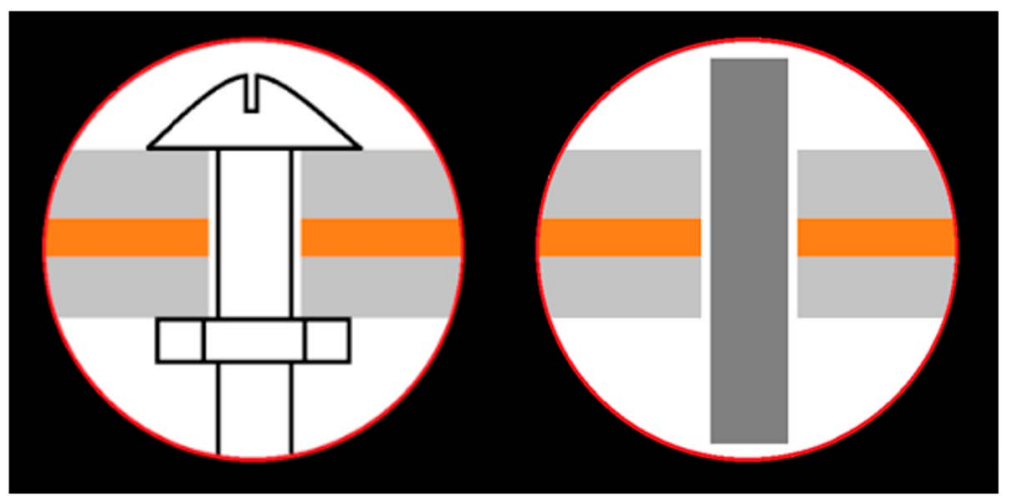

Figure 3. Comparison of bolt and pin.

\subsection{Manufacturing the Test Specimens}

The adherends were made of aluminum alloy 2024-T3 and were cut by a shear cutter into $102.5 \mathrm{~mm} \times 25 \mathrm{~mm}, 115 \mathrm{~mm} \times 25 \mathrm{~mm}, 130 \mathrm{~mm} \times 25 \mathrm{~mm}$, and $190 \mathrm{~mm} \times 25 \mathrm{~mm}$ specimens. 2.5-mm-diameter holes for fastening the peel-stop fasteners were drilled into the specimens by using a drilling machine. Figure 4 shows the dimensions of the specimens.

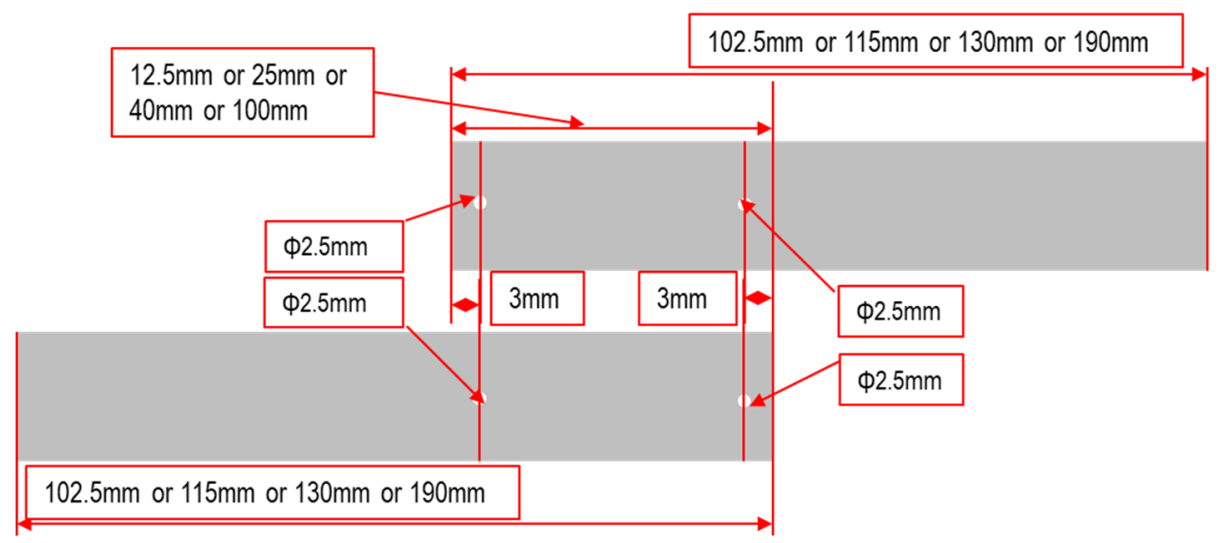

Figure 4. The dimensions of the specimens.

The surface to bond was polished by \#180 sandpaper and by IPA (isopropyl alcohol) to remove water-soluble stains. Moreover, it was polished by acetone to remove oil-soluble stains. Stainless wire, which was used to maintain the thickness of the adhesives, was also polished by IPA and acetone and fixed with masking tape. Adhesive AV138 and hardener 
HV998 were mixed in a weight ratio of 5:2. The mixed adhesive was applied to, i.e., rubbed on, both surfaces of the adherends and then fixed to a curing alignment fixture, as shown in Figure 5.

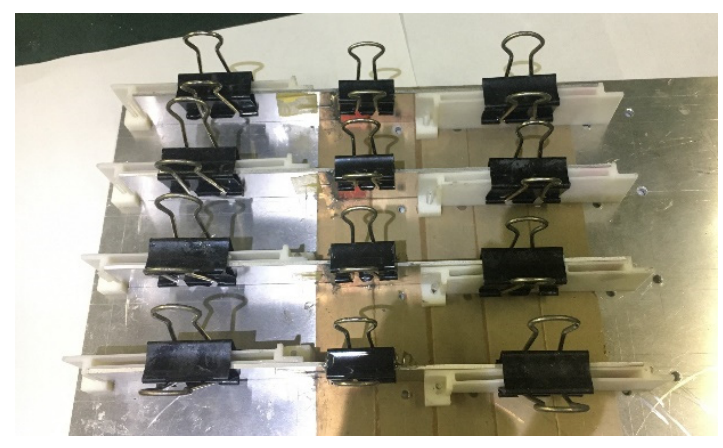

Figure 5. Curing alignment fixture.

The brass and nylon bolts were fixed before adhesive curing. In the case of curing the specimens with steel pins, temporary fixing pins were used to prevent the peel-stopper effect of the steel pins; when the adhesive had partially hardened, they were replaced with release-agent-applied steel pins. To prevent thermal residual stress, the adhesive was cured at room temperature.

\section{Lap Shear Test}

The lap shear test was conducted on a universal testing instrument (Shimadzu AG-I $100 \mathrm{kN}$, load accuracy within $\pm 1 \%$ of the indicated value). Support fixtures with an anti-slipping agent (sandpaper with double-sided tape) were used to apply tension force at the center of the adhesive, as shown in Figure 6.

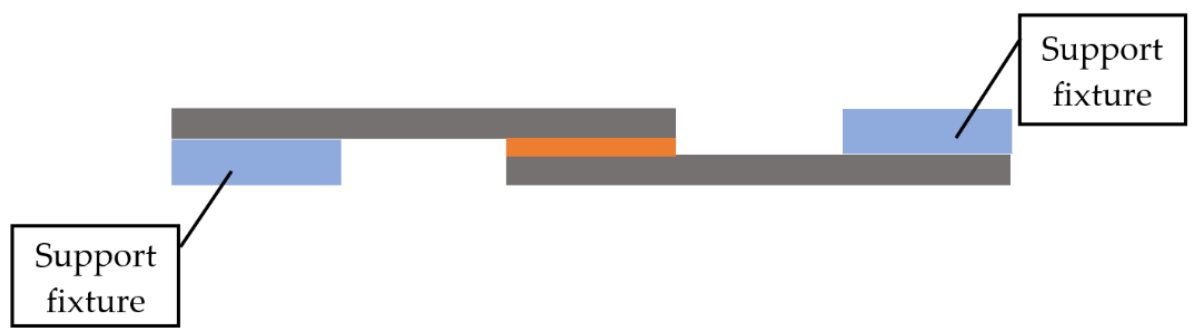

Figure 6. Support fixtures.

The specimens in the lap shear test were clamped to the chuck of the universal testing instrument with support fixtures. The load and crosshead displacement were measured; the crosshead speed was $1 \mathrm{~mm} / \mathrm{min}$, and tension force was applied until the adherend separated completely.

Figure 7 shows two failure modes: adhesive failure and tension failure across the hole. 

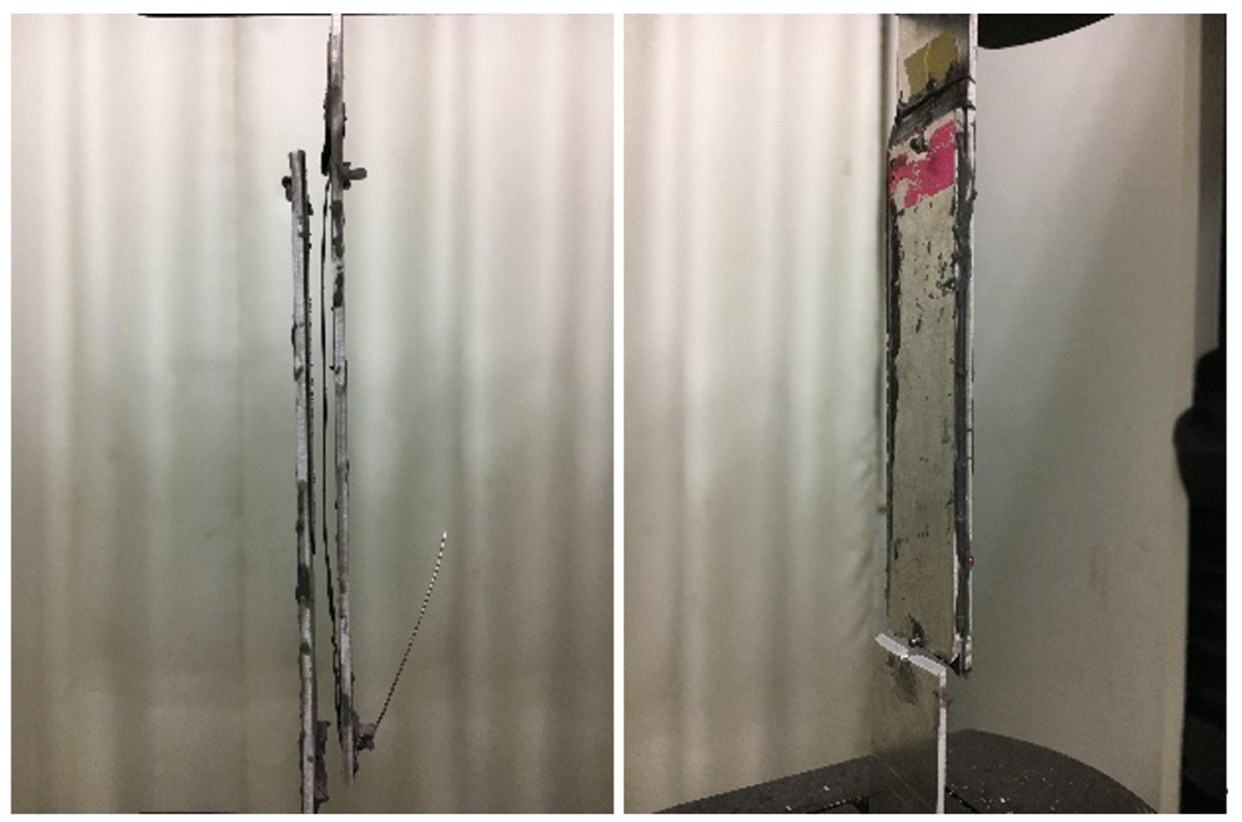

Figure 7. Adhesive failure (left) and tension failure across the hole (right).

\section{Test Results}

\subsection{5-mm Lap Length}

Figure 8 shows the mean shear stress $\tau=P /\left(b l_{2}\right)$, where $P$ is the maximum test load, $b$ is the width of the adherend, and $l_{2}$ is the bonded length, as in Figure 4 . Note that the numbers in Figure 8 are the mean values of two samples as indicated by the two bars of different color. No significant effect of the peel stoppers or steel pins was observed. All specimens failed in adhesive failure mode (Figure 9).

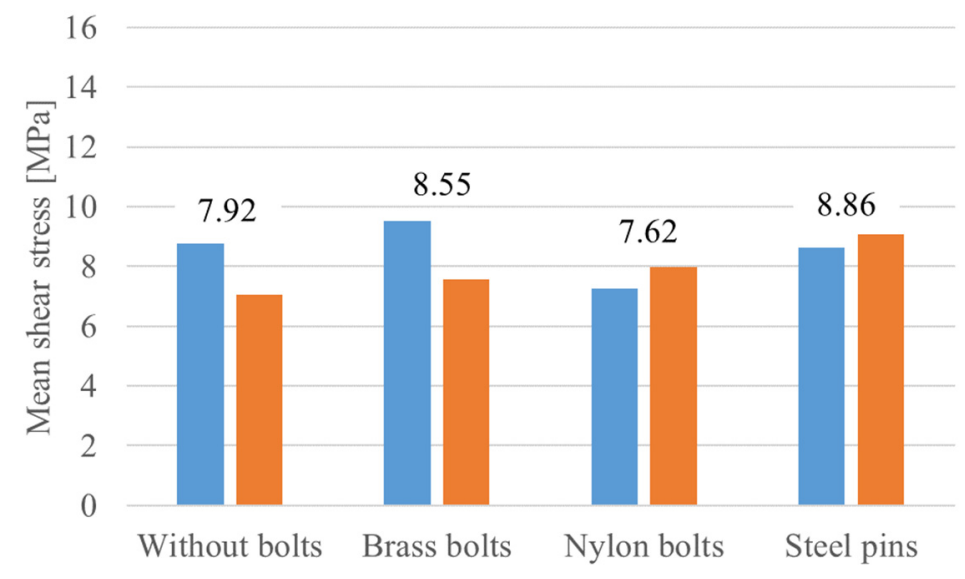

Figure 8. Mean shear stress for a 12.5-mm lap length. 


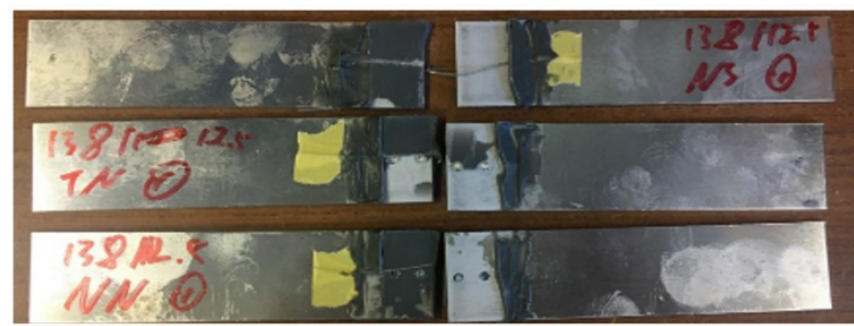

\section{Without bolts. No.1}

Brass bolts. No.1

Nylon bolts. No.1

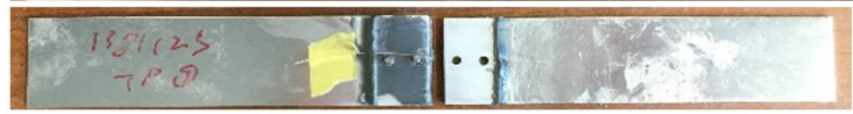

Steel pins. No.1

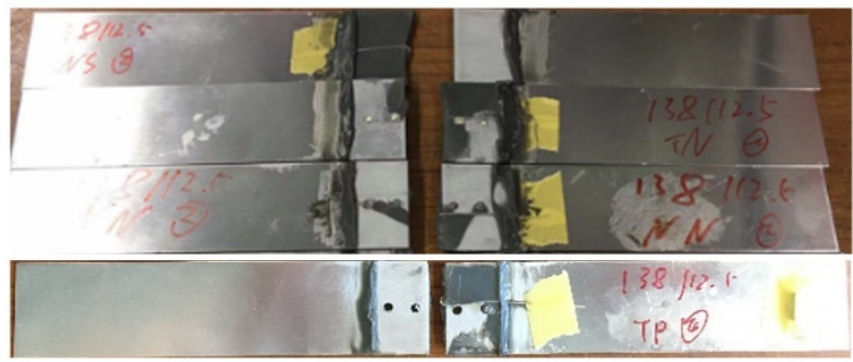

Without bolts. No.2

Brass bolts. No.2

Nylon bolts. No. 2

Steel pins. No.2

Figure 9. Failure modes of specimens with a 12.5-mm lap length.

\subsection{5-mm Lap Length}

Figure 10 shows the mean shear stress for a lap length of $25 \mathrm{~mm}$. All specimens failed in adhesive failure mode (Figure 11). The mean shear stress of the specimens with the brass bolts was rather higher than that of those without bolts, while the mean shear stress of those with nylon bolts was slightly higher.

\subsection{0-mm Lap Length}

Figure 12 shows the mean shear stress for the lap length of $40 \mathrm{~mm}$. All specimens failed in adhesive failure mode (Figure 13). The mean shear stress of specimens with brass and nylon bolts was higher than those without bolts, while no improvement was observed for specimens with a steel pin.

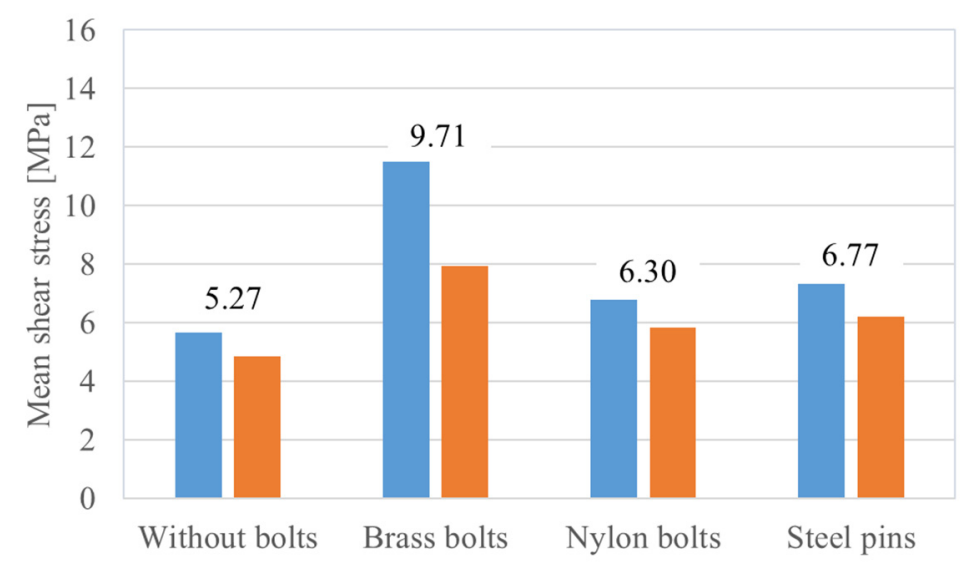

Figure 10. Mean shear stress for a 25-mm lap length. 


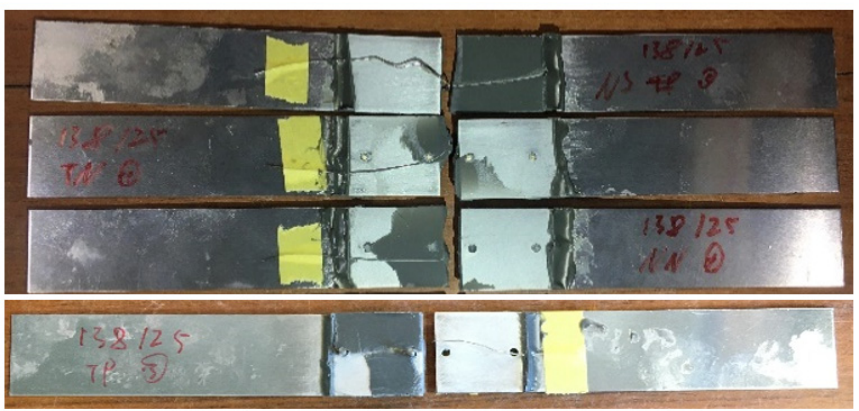

Without bolts. No.1

Brass bolts. No.1

Nylon bolts. No.1

Steel pins. No.1

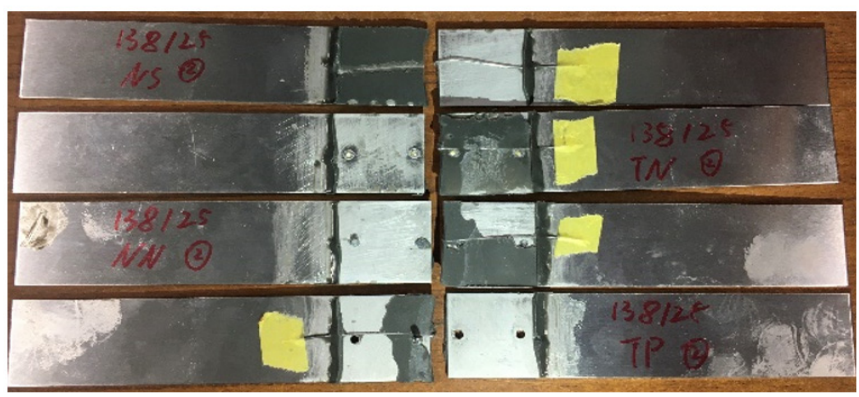

\section{Without bolts. No.2}

Brass bolts. No. 2

Nylon bolts. No. 2

Steel pins. No.2

Figure 11. Failure modes of specimens with a 25-mm lap length.

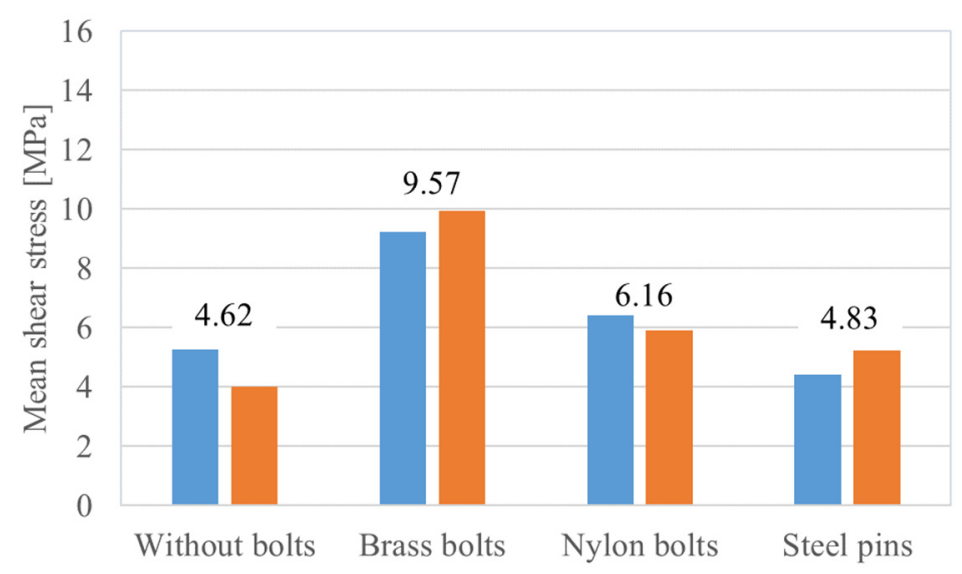

Figure 12. Mean shear stress for a 40-mm lap length.

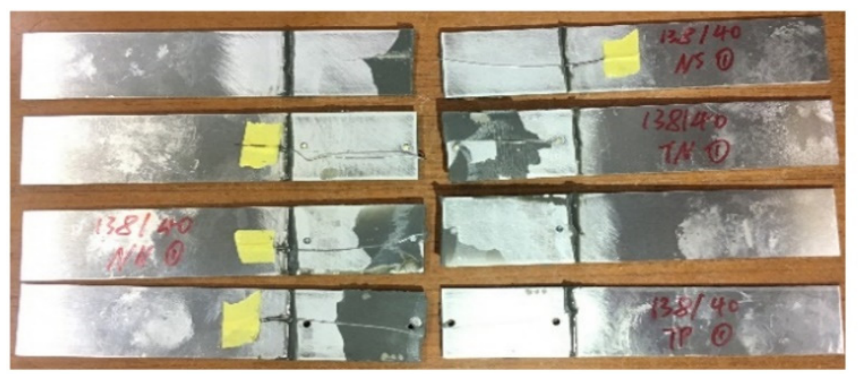

Without bolts. No.1

Brass bolts. No.1

Nylon bolts. No.1

Steel pins. No.1

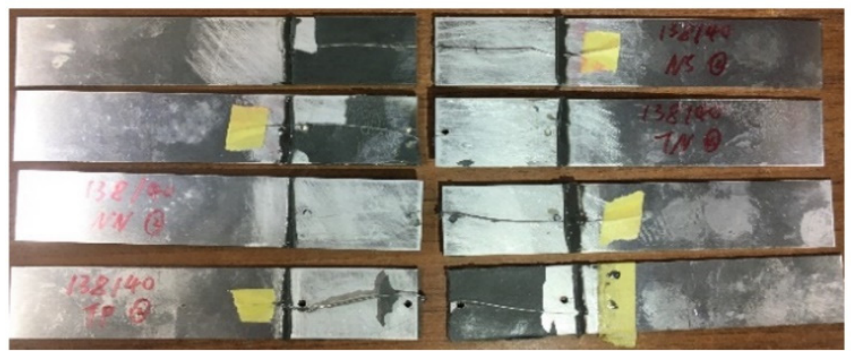

Without bolts. No.2

Brass bolts. No.2

Nylon bolts. No.2

Steel pins. No.2

Figure 13. Failure modes of specimens with a 40-mm lap length. 


\subsection{0-mm Lap Length}

Figure 14 shows the mean shear stress for a lap length of $100 \mathrm{~mm}$. The red line is the converted mean shear stress, $6.34 \mathrm{MPa}$, from the tensile strength of the 2024-T3 adherend $\left(\sigma_{t u}=440 \mathrm{MPa}\right)$, which was calculated as $\tau=\sigma_{t u}(b-d) t_{1} /\left(b l_{2}\right)$. The mean shear stress of the specimens with brass bolts was close to the adherend tensile strength. Figure 15 shows failure modes of specimens with a $100-\mathrm{mm}$ lap length. Specimens without a peel stopper and with nylon bolts failed in adhesive failure mode, while specimens with brass bolts suffered tension failures across the hole mode. The specimens with steel pins failed in adhesive failure mode and experienced tension failures across the hole mode. The mean shear stress of specimens with brass bolts was significantly improved relative to that of specimens without a peel stopper, while that of specimens with nylon bolts slightly improved. The mean shear stress of specimens with steel pins showed significant scatter and was lower than that of specimens without peel stoppers.

\subsection{Peel Stoppers without Adhesive}

A lap shear test of peel stoppers without adhesive was conducted on the specimen with a $100 \mathrm{~mm}$ lap length. The mean values of the measured converted mean shear stresses were $751.1 \mathrm{~N}$ for brass bolts and $154.2 \mathrm{~N}$ for nylon bolts. The converted mean shear stress of steel pins could not be measured because the steel pins were pulled out of the adherend during the lap shear test. Figures 16 and 17 show the converted mean shear stress for lap lengths of 12.5, 25, 40 and $100 \mathrm{~mm}$ for brass bolts and nylon bolts, respectively. The results show that the lap shear strength with peel stoppers was higher than the sum of strength without peel stoppers or the strength of peel stoppers, with the exception of the $12.5 \mathrm{~mm}$ lap length.

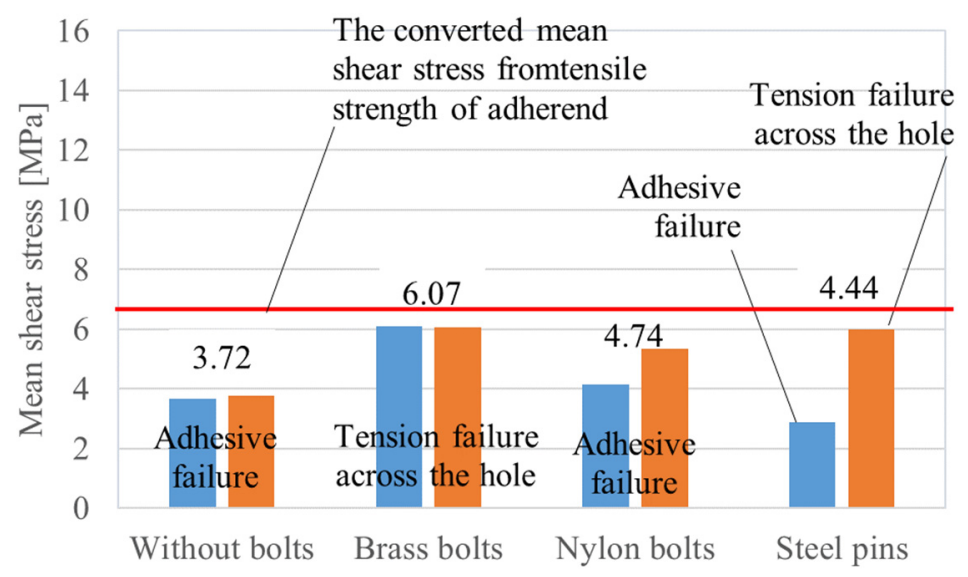

Figure 14. Mean shear stress for a 100-mm lap length. 


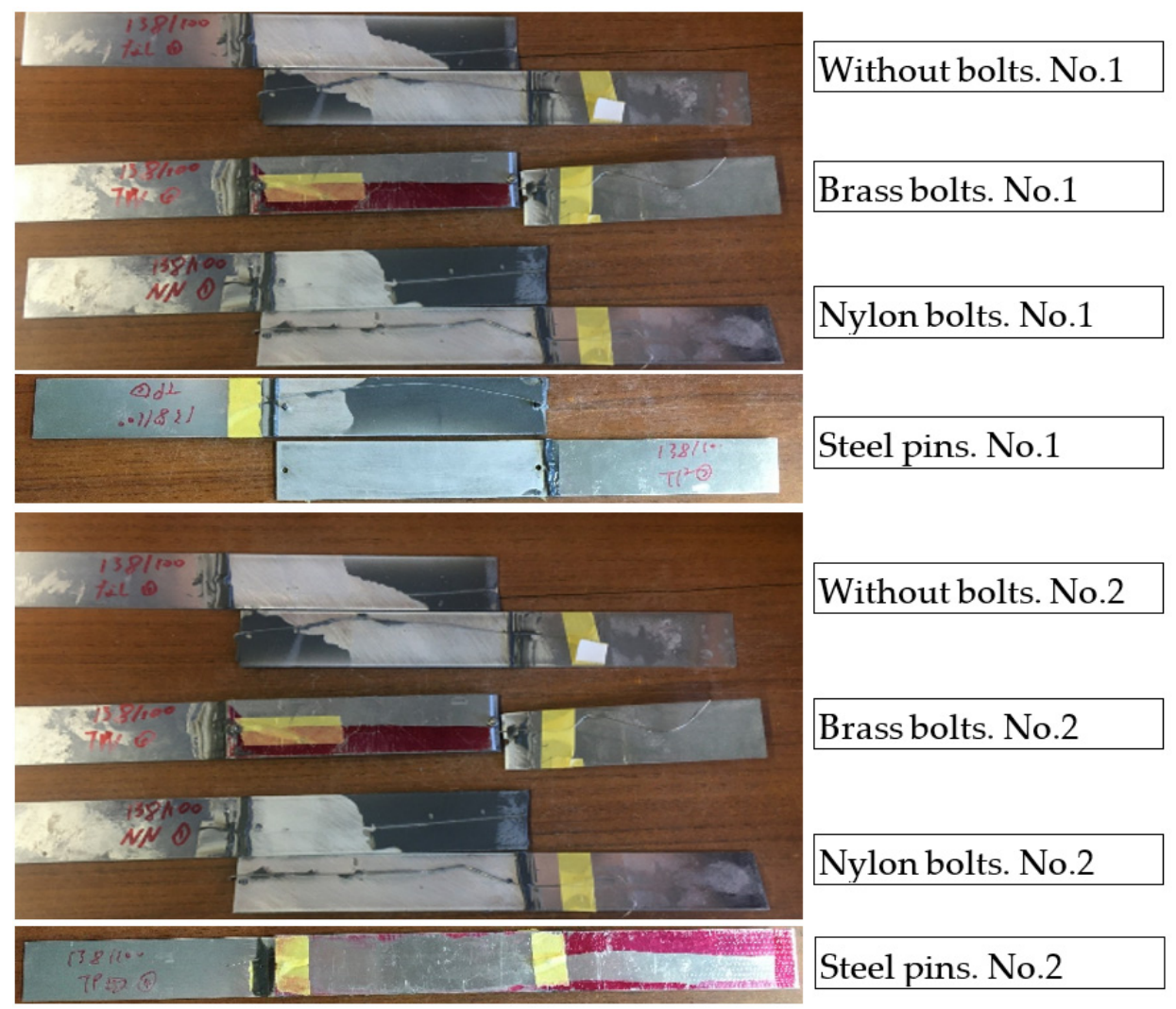

Figure 15. Failure modes of specimens with a 100-mm lap length.

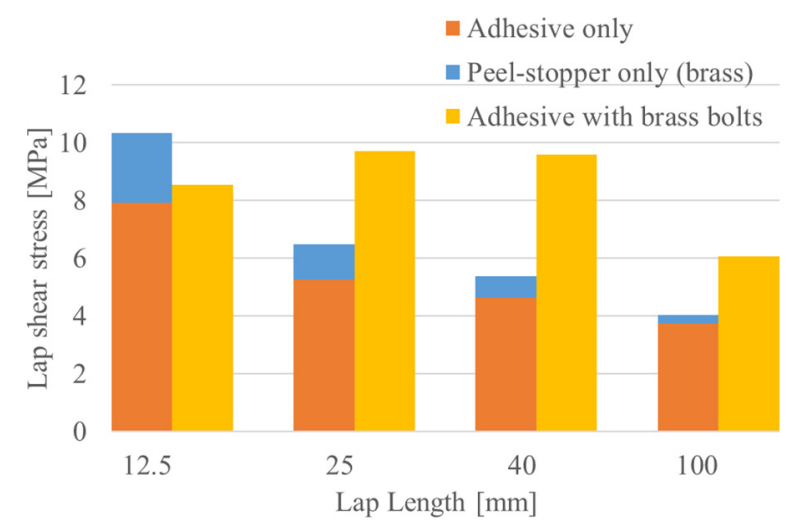

Figure 16. Peel-stopper effect of brass bolts.

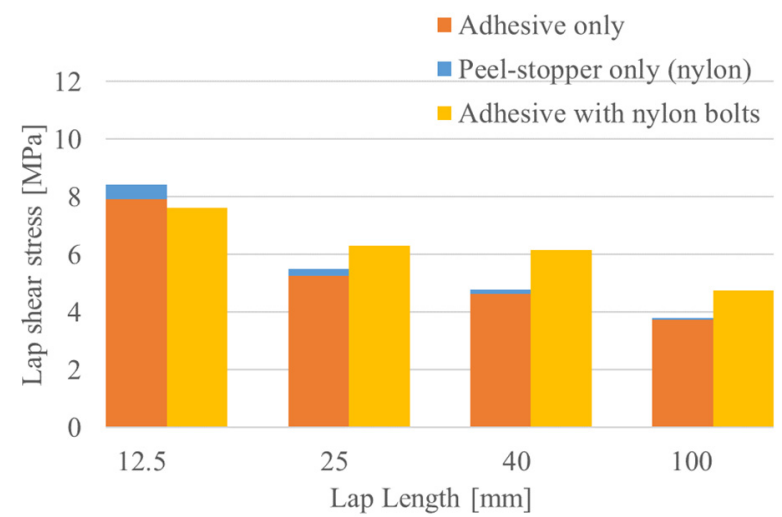

Figure 17. Peel-stopper effect of nylon bolts. 


\section{Discussion}

As shown Figures 16 and 17, no improvement was observed in the case of a lap length of $12.5 \mathrm{~mm}$, because the peel stress was not significant. The improvements shown for lap lengths of 25, 40, and $100 \mathrm{~mm}$ were significant; the values were much higher than the converted mean shear stress of the peel stoppers because the peel stress is significant due to the long lap length. These results indicate that the effect is caused by the stiffness of the peel stoppers, not the shear strength.

As shown in Figure 14, a single sample with a lap length of $100 \mathrm{~mm}$ with steel pins significantly improved compared with the samples with steel pins and lap lengths of 25 and $40 \mathrm{~mm}$. The reason is that the steel pins stuck in spite of the release agent, generating the peel stopper effect.

As shown in Figure 15 (lap length of $100 \mathrm{~mm}$ ), for brass bolts, the failure load reached the tension strength of the adherends. On the other hand, lap lengths of 25 and $40 \mathrm{~mm}$ with brass bolts experienced adhesive failure, as shown in Figures 9, 11 and 13. These results show that failure load increases with increasing lap length for brass bolts, despite lap shear stress decreases with increasing lap length.

A simulation is required for predicting the strength of adhesive joints for design purposes. The author, however, cannot find a reliable analytical or numerical method for predicting the strengths of lap shear joints without peel-stop fasteners. Thus, at present it remains hard to establish a strength prediction method for lap shear joints with peel-stop fasteners, and more analytical and experimental studies are required.

\section{Conclusions}

The lap shear strength was significantly improved by the peel stopper effect of brass and nylon bolts. The peel stopper effect of brass bolts was higher than that of nylon bolts. The lap shear strength of nylon bolts was lower than that of brass bolts but higher than it would be without peel stoppers. The peel stopper effect of brass bolts increased with lap length. The improvement experienced by steel pins was not significant. Thus, the peel stopper effect increases lap shear strength more than reinforcement by shear pins.

Author Contributions: Conceptualization, A.T.; methodology, A.T. and C.L.; validation, A.T.; formal analysis, C.L; writing—original draft preparation, A.T.; writing—review and editing, A.T. and R.K. All authors have read and agreed to the published version of the manuscript.

Funding: This research received no external funding.

Institutional Review Board Statement: Not applicable.

Informed Consent Statement: Not applicable.

Data Availability Statement: The data presented in this study are available on request from the corresponding author.

Conflicts of Interest: The authors declare no conflict of interest.

\section{References}

1. Volkersen, O. Nietkraftverteiligung in Zugbeanspruchten Nietverbindungen mit Konstanten Laschenquerschnitten. Luftfahrtforschung 1938, 15, 41-68.

2. Hart-Smith, L.J. Adhesive-Bonded Single-Lap Joints; NASA CR-112236; Technical Report for Langley Research Center: Hampton, VA, USA, January 1973.

3. Goland, M.; Reissner, E. The Stresses in Cemented Joints. J. Appl. Mech. 1944, 11, 17-27.

4. Oplinger, D.W. Effects of Adherend Deflections in Single Lap Joints. Int. J. Solids Struct. 1994, 31, 2565-2587. [CrossRef]

5. Ojalvo, I.U.; Eidinoff, H.L. Bond Thickness Effects upon Stresses in Single-Lap Adhesive Joints. AIAA J. 1978, 16, $204-211$. [CrossRef]

6. Awalekar, Y.A.; Takalkar, A.S.; Shinde, S.S. Investigation of Peel Resistance of Adhesives Materials: A Review. Proc. Eng. Technol. Innov. 2018, 10, 19-28.

7. Kawashita, L.F.; Kinloch, A.J.; Moore, D.R.; Williams, J.G. The Influence of Bond Line Thickness and Peel Arm Thickness on Adhesive Fracture Toughness of Metal Polymer Laminates. Int. J. Adhes. Adhes. 2008, 28, 199-210. [CrossRef] 
8. Pereira, A.M.; Ferreira, J.M.; Antunes, F.V.; Bártolo, P.J. Analysis of manufacturing parameters on the shear strength of aluminium adhesive single-lap joints. J. Mater. Process. Technol. 2010, 210, 610-617. [CrossRef]

9. da Silva, L.F.M.; Rodrigues, N.S.S.; Figueiredo, M.A.V.; de Moura, M.F.S.F.; Chousal, J.A.G. Effect of Adhesive Type and Thickness on the Lap Shear Strength. J. Adhes. 2006, 82, 1091-1115. [CrossRef]

10. Boutar, Y.; Naïmi, S.; Mezlini, S.; Ali, M.B.S. Effect of surface treatment on the shear strength of aluminium adhesive single-lap joints for automotive applications. Int. J. Adhes. Adhes. 2016, 67, 38-43. [CrossRef]

11. Chowdhury, S.H.; Chen, D.L.; Bhole, S.D.; Cao, X.; Wanjara, P. Lap shear strength and fatigue behavior of friction stir spot welded dissimilar magnesium-to-aluminum joints with adhesive. Mater. Sci. Eng. A 2013, 562, 53-60. [CrossRef]

12. Zhou, W.; Ai, S.; Chen, M.; Zhang, R.; He, R.; Fang, D. Preparation and thermodynamic analysis of the porous $\mathrm{ZrO}_{2} /\left(\mathrm{ZrO}{ }_{2}+\mathrm{Ni}\right)$ functionally graded bolted joint. Compos. Part B Eng. 2015, 82, 13-22. [CrossRef]

13. Zhou, W.; Zhang, R.; Ai, S.; He, R.; Pei, Y.; Fang, D. Load distribution in threads of porous metal-ceramic functionally graded composite joints subjected to thermomechanical loading. Compos. Struct. 2015, 134, 680-688. [CrossRef]

14. Zhou, W.; Zhang, R.; Fang, D. Design and analysis of the porous $\mathrm{ZrO}_{2} /\left(\mathrm{ZrO}_{2}+\mathrm{Ni}\right)$ ceramic joint with load bearing-heat insulation integration. Ceram. Int. 2016, 42, 1416-1424. [CrossRef] 